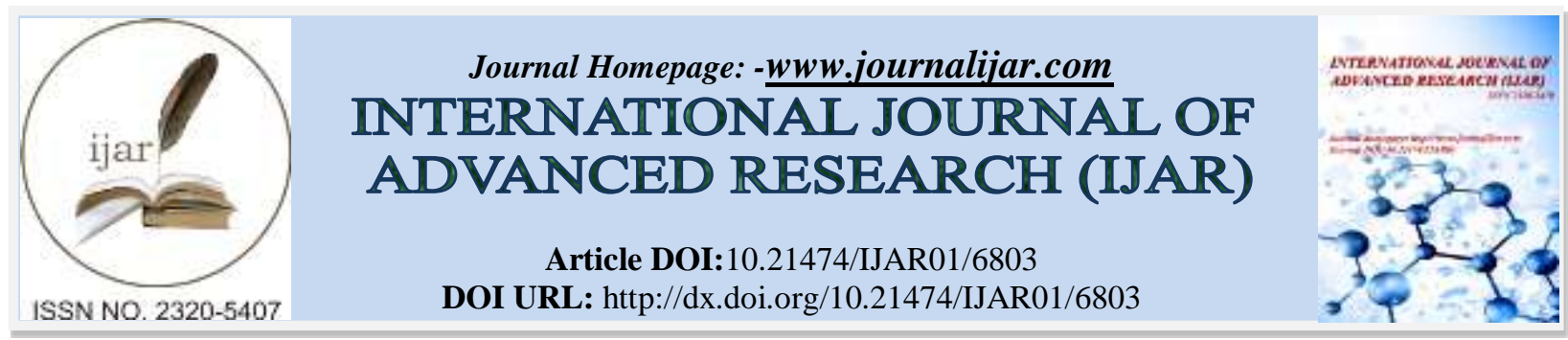

RESEARCH ARTICLE

\title{
A STUDY TO DETERMINE VISUAL DISABILITY IN A TERTIARY EYE CARE CENTRE IN STATE OF ODISHA.
}

Dr. Suresh Chandra Swain ${ }^{1}$, Dr. Deepak Choudhury ${ }^{2}$, Dr. Sumita Mohapatra ${ }^{3}$, Prof. Prasant Kumar Nanda ${ }^{4}$, Dr. Balakrushna Samantray ${ }^{5}$, Dr. Kumari Krishna Patra ${ }^{5}$ and Dr. Bijay Kumar Pattnaik ${ }^{5}$.

1. Associate professor, RIO, SCB Medical College, Cuttack, Odisha.

2. Senior Resident, RIO, SCB Medical College, Cuttack, Odisha.

3. Professor and HOD, RIO, SCB Medical College, Cuttack, Odisha.

4. Professor, RIO, SCB Medical College, Cuttack, Odisha.

5. Asst. prof, RIO, SCB Medical College, Cuttack, Odisha.

\section{Manuscript Info}

-.......................

Manuscript History

Received: 21 January 2018

Final Accepted: 23 February 2018

Published: March 2018

\section{Keywords:-}

visual disability, certification, medical board

\section{Abstract}

Objective:- to determine visual disability in a tertiary eye care centre in state of Odisha. Introduction:- The minimum degree of disability should be $40 \%$ for an individual to avail benefits. Prevention of visual impairment and rehabilitation of visually impaired requires data regarding incidence and etiologies of blindness. Materials and methods:- This was a cross- sectional study done in weekly basis for a period of 2 years from April 2015 to March 2017. Study involved 109 patients with visual disability of $30 \%$ or above. The percentage of disability was calculated based on the guidelines for the evaluation of various disabilities and procedure for certification. Results:- 185 eyes of 109 patients were disabled. Male to female ratio was 1.94: 1. 32.1\% patients were $100 \%$ disabled. $40 \%$ disabled persons were more in number i.e. $37.6 \%$. Age range was 7- 50 years with mean age of 23.29 \pm 7.34 years. Amblyopia was the most common cause of visual disability. 55.7\% patients had some congenital and developmental anomalies. Conclusion:- Male and young adults were more in number. Amblyopia was the most common cause.

Copy Right, IJAR, 2018,. All rights reserved.

\section{Introduction:-}

Registration of blind or partial sighted in India is performed by certification by ophthalmologist. According to Ministry of Social justice and Empowerment of Government of India, the minimum degree of disability should be $40 \%$ for an individual to avail benefits. ${ }^{[1]}$ Disability is defined as any restriction or lack of abilities to perform an activity in the manner or within the range considered normal for an individual. ${ }^{[2]}$ Prevention of visual impairment and rehabilitation of visually impaired requires data regarding incidence and etiologies of blindness.

The objective of our study were to analyze the medically certified visually disabled individual based on degree of disability and the cause of visual disabilityin the tertiary eye care centre in the State of Odisha. 


\section{Materials \&Methods:-}

This study included 109 patients with visual disability of $30 \%$ or above. 185 eyes of 109 patients were found to be visually disabled. Cross sectional study was done in weekly basis in the tertiary care centre. Selected patients were referred from various district headquarter hospitals of Odisha state. Duration of study was 2 years (from April 2015 to March 2017). The percentage of disability was calculated based on the guidelines for the evaluation of various disabilities and procedure for certification by Government of India (Table-1). We included all cases certified by the medical board over a two year period. Referred patients attending the board were examined in the outpatient department (OPD). Diagnosis was based on medical history, clinical examination and special investigation such as automated perimetry, ocular coherence tomography (OCT), fundus photograph when necessary.

\section{Inclusion criteria:-}

1. Persons having disability $30 \%$ or above

2. Those who have attended medical board at a tertiary care hospital of Odisha.

\section{Exclusion criteria:-}

1. Patients with preventable blindness.

Table1:- Categories of visual disability

\begin{tabular}{|l|l|l|}
\hline Best corrected visual acuity in the better eye & \multicolumn{1}{|c|}{ Best corrected visual acuity in the worse } & \multicolumn{1}{|c|}{$\begin{array}{c}\text { Percentage of } \\
\text { impairment }\end{array}$} \\
\hline $6 / 18-6 / 36$ & $6 / 60$ to nil & $40 \%$ \\
\hline $6 / 60-4 / 60$ or field of vision $10^{0}$ to $20^{\circ}$ & $3 / 60$ to nil & $75 \%$ \\
\hline $3 / 60-4 / 60$ or field of vision $10^{0}$ & Finger count at $1 \mathrm{ft}$ to nil & $100 \%$ \\
\hline $\begin{array}{l}\text { Finger count at } 1 \mathrm{ft} \text {. to nil or field of vision } \\
10^{0}\end{array}$ & Finger count at $1 \mathrm{ft}$. of field or vision $10^{0}$ & $100 \%$ \\
\hline $6 / 6$ & F.C. at $1 \mathrm{ft}$. to Nil or field of vision $10^{0}$ & $30 \%$ \\
\hline
\end{tabular}

\section{Results:-}

The study was conducted on 109 patients. Out of them 72 patients were male and 37 were female. Male: Female ratio was 1.94:1. $35(32.1 \%)$ patients were $100 \%$ disabled, $8(7.3 \%)$ were $75 \%, 41(37.6 \%)$ were $40 \%$ and 25 (22.9\%) were $30 \%$ disabled. The male: female ratio were $4: 1,1: 1,1.73: 1,1.27: 1$ among $100 \%, 75 \%, 40 \%$ and $30 \%$ disabled groups respectively.

Table 1:- Distribution of visually disabled individual according to age, gender and percentage.

\begin{tabular}{|l|l|l|l|l|l|l|l|l|}
\hline \% Disability $\rightarrow$ & $\mathbf{1 0 0 \%}$ & $\mathbf{7 5 \%}$ & $\mathbf{4 0 \%}$ & $\mathbf{3 0 \%}$ \\
\hline Age group $\downarrow$ & $\mathbf{M}$ & $\mathbf{F}$ & $\mathbf{M}$ & $\mathbf{F}$ & $\mathbf{M}$ & $\mathbf{F}$ & $\mathbf{M}$ & F \\
\hline 5- 10 & 0 & 0 & 0 & 0 & 3 & 0 & 0 & 0 \\
\hline $\mathbf{1 1 - 2 0}$ & 6 & 1 & 3 & 1 & 6 & 13 & 6 & 3 \\
\hline $\mathbf{2 1 - 3 0}$ & 17 & 5 & 1 & 3 & 13 & 2 & 2 & 7 \\
\hline $\mathbf{3 1 - 4 0}$ & 3 & 1 & 0 & 0 & 3 & 0 & 0 & 1 \\
\hline 41- 50 & 2 & 0 & 0 & 0 & 1 & 0 & 1 & 0 \\
\hline
\end{tabular}

Age range was 7-50 years with mean age of $23.29 \pm 7.34$ years, median of 22 years of age and mode of 20 years. 65 patients $(59.6 \%)$ were in working age group (21- 50 years) and 44 patients $(40.3 \%)$ were $\leq 20$ years.

Table- 2:- Disability of eyes with disability according to causative factors.

\begin{tabular}{|l|c|c|c|}
\hline \multicolumn{1}{|c|}{ Cause } & Both eye & One eye & Total Eyes (n=185) \\
\hline Absolute eye & 0 & 2 & 2 \\
\hline Amblyopia & 11 & 8 & 30 \\
\hline Anophthalmos & 6 & 1 & 13 \\
\hline Ant. staphyloma & 0 & 4 & 4 \\
\hline Central corneal opacity & 8 & 3 & 19 \\
\hline Myopic degeneration & 13 & 3 & 29 \\
\hline Microcornea & 6 & 6 & 18 \\
\hline Macular dystrophy & 3 & 0 & 6 \\
\hline
\end{tabular}




\begin{tabular}{|l|c|c|c|}
\hline Microphthalmos & 6 & 7 & 19 \\
\hline Nanophthalmos & 1 & 1 & 3 \\
\hline Optic atrophy & 3 & 1 & 14 \\
\hline Pthisisbulbi & 2 & 10 & 1 \\
\hline Retinoblastoma & 0 & 1 & 2 \\
\hline Retinal detachment & 0 & 2 & 2 \\
\hline Retinitis pigmentosa & 1 & 0 & 1 \\
\hline Socket eye & 0 & 1 & 4 \\
\hline Choroidal coloboma & 4 & 3 & 4 \\
\hline Macular scar & 2 & 0 & \\
\hline
\end{tabular}

Amblyopia was the most common cause of visual disability in this study being present in 30 eyes (16.2\%). Among Amblyopic patients 14 (7.6\%) patients had strabismic amblyopia, $11(5.9 \%)$ had refractive and $5(2.7 \%)$ had stimulus deprivation amblyopia. Myopic degeneration was the second common cause being present in 29 eyes $(15.7 \%)$, followed by both central corneal opacity and microphthalmos in 19 eyes each (10.2\%). Microcornea was present in 18 eyes (9.7\%). Choroidal coloboma with microcornea was present in 11 eyes (5.9\%). 103 eyes (55.7\%) were visually disabled due to some congenital or developmental anomalies.

\section{Discussion:-}

In our study the number of males attending to the medical board to obtain the disability certificate was significantly higher than that of females. Young patients were in a significant majority compared to elderly. Young patients are more likely willing to get benefits of employment, education by producing disability certificate. Majority of patients, $41(37.6 \%)$ have $40 \%$ disability in our study. Amblyopia was most common cause of disability (16.2\%). Ghosh et al in a study of 155 visually disabled individuals found pthisis bulbi as the major cause. They found congenital and developmental anomalies were present in $38.71 \%{ }^{[3]}$ However in our study congenital and developmental anomalities present as high as $55.7 \%$ of eyes. Patients with amblyopia, anophthalmos, microcornea, macular dystrophy, microphthalmos, nanophthalmos, retinoblastoma, retinitis pigmentosa, choroidal coloboma were included in congenital and developmental anomaly group. Strabismic amblyopia was the most common type among the patients amblyopia. Since a large number of patients attending the medical certification board were of younger age group, hence those classified under congenital and developmental anomalies were more in number. Gibson et al in a study found that the blind register had high sensitivity and specificity, but it underestimated the prevalence of blindness by a factor of 1.1. ${ }^{[4]}$ In our study, the prevalence of visual disability could not be calculated due to lack of proper denominator; and also we could not estimate the sensitivity and specificity of the blind register. This was the limitation of our study.

\section{Conclusion:-}

Large number of disabled individuals comprised of young adults. Number of males was significantly higher than females. Amblyopia was the most common cause. Similar studies should be done in a regular interval in all parts of India to evaluate the certification programme for visually disabled individuals.

\section{References:-}

1. Guidelines for evaluation of various disabilities and procedure for certification. The Gazette of India extraordinary. Part 1. Section 1. No 154.

2. National Sample Survey Organization, Ministry of Statistics and Programme Implementation, Government of India, Round number $58^{\text {th }}$ in 2002.

3. Ghosh S, Mukhopadhyay S, Sarkar K. Evaluation registered visually disabled individuals in a district of West Bengal, India. Indian journal of community medicine. 2008 July; 33(3): 168-71.

4. Gibson J, Lavery J, Rosenthal A. Blindness and partial sight in an elderly population. British journal of ophthalmology. 1986; 70(9): 700-5. 